Heat of Combustion of

Tantalum-Tungsten Oxide

Thermite Composites

Octavio Cervantes, Joshua Kuntz, Alexander Gash, Zuhair Munir

November 12, 2009

Combustion and Flame 
This document was prepared as an account of work sponsored by an agency of the United States government. Neither the United States government nor Lawrence Livermore National Security, LLC, nor any of their employees makes any warranty, expressed or implied, or assumes any legal liability or responsibility for the accuracy, completeness, or usefulness of any information, apparatus, product, or process disclosed, or represents that its use would not infringe privately owned rights. Reference herein to any specific commercial product, process, or service by trade name, trademark, manufacturer, or otherwise does not necessarily constitute or imply its endorsement, recommendation, or favoring by the United States government or Lawrence Livermore National Security, LLC. The views and opinions of authors expressed herein do not necessarily state or reflect those of the United States government or Lawrence Livermore National Security, LLC, and shall not be used for advertising or product endorsement purposes. 


\title{
Heat of Combustion of Tantalum-Tungsten Oxide Thermite Composites
}

\author{
Octavio G. Cervantes* ${ }^{+}$, Joshua D. Kuntz*, Alexander E. Gash*, and Zuhair A. Munir ${ }^{+}$ \\ *Physical and Life Sciences Directorate, Lawrence Livermore National Laboratory \\ ${ }^{+}$Department of Chemical Engineering \& Materials Science \\ University of California, Davis, CA 95616
}

\begin{abstract}
The heat of combustion of two distinctly synthesized stoichiometric tantalum-tungsten oxide energetic composites was investigated by bomb calorimetry. One composite was synthesized using a sol-gel (SG) derived method in which micrometric-scale tantalum is immobilized in a tungsten oxide three-dimensional nanostructured network structure. The second energetic composite was made from the mixing of micrometric-scale tantalum and commercially available (CA) nanometric tungsten oxide powders. The energetic composites were consolidated using the spark plasma sintering (SPS) technique under a $300 \mathrm{MPa}$ pressure and at temperatures of 25, 400 , and $500^{\circ} \mathrm{C}$. The densities of both energetic composites are similar for samples consolidated at 400 and $500^{\circ} \mathrm{C}$. For samples consolidated at $25^{\circ} \mathrm{C}$, the density of the CA composite is about $10 \%$ higher than the SG derived composite. X-ray diffraction analyses showed an increase of pre-combustion reaction of the constituents with an increase in the consolidation temperature. The increase in pre-combustion reaction results in lower stored energy content for samples consolidated to 400 and $500^{\circ} \mathrm{C}$ in comparison to samples consolidated at $25^{\circ} \mathrm{C}$.
\end{abstract}

\section{Introduction}

Nanostructured materials have been the focus of considerable interest due to their potential and demonstrated enhanced properties. An area where these materials have gained considerable interest is energetic composites. Energetic nano-composites are of significant interest due to the wide range of material properties that can be tailored by controlling their chemical and physical composition. It is understood that the reactants in energetic nano-composites have one or both reactants in the nanometric scale. Presently, there are several methods for synthesizing energetic composites. They can be prepared as films deposited on substrates. These films may be composed of alternating metallic layers ${ }^{1,2}$ or layers of metal fuel and metal oxide with well defined thickness and composition ${ }^{3}$. A major disadvantage to this approach is that it is time 
consuming, expensive, and yields relatively small amounts of material. Another method for synthesizing energetic composites involves the ultrasonic mixing of fuel and oxidizer nanoparticles. Such subset of energetic composites has been referred to as Metastable Interstitial Composites (MIC) ${ }^{4}$. And although, this process is relatively inexpensive and large quantities of material can be prepared quickly, an important concern is the homogeneity of the fuel and oxidizer mixture to minimize variability in their thermal behavior. Additionally, another method for producing energetic materials includes arrested reactive milling (ARM). In this method exothermic nano-energetic composites are prepared by mechanically milling the starting metal fuel and metal oxide mixture but stopping the milling process before the mixture reacts exothermally. ${ }^{5-7}$. A third method to synthesize energetic composites consists of immobilizing metal fuels inside nanometric oxidizers via sol-gel synthesis ${ }^{8-10}$. This method produces an energetic composite in which the metal fuel is homogeneously distributed throughout the nanometric oxidizer, and it can be scaled up to produce large sample quantities.

In addition to investigations on the synthesis and characterization of energetic composites, efforts have been made to determine the performance of the thermite reactions. Several researchers have investigated the ignition sensitivity, energy release rates, and the activation energies of energetic composites as a function of fuel particle size. Grainer, et al. ${ }^{11}$, reported that the ignition behavior of nanometric aluminum-based thermites is significantly different than that of micrometric thermites. Moreover, Aumann, et al. ${ }^{12}$, reported that $\mathrm{Al}$ and $\mathrm{MoO}_{3}$ powder mixtures with average particle sizes in the range of $20-50 \mathrm{~nm}$ reacted about 1000 times faster than conventional micrometric thermites. This was attributed to the reduced diffusion lengths between individual reactant particles. While considerable efforts have been aimed at understanding key properties such as reaction mechanisms, ignition sensitivity, energy release rates and activation energies, there appears to be a lack of studies on the heat of combustion of such energetic composites. In addition, studies on the effects of processing parameters have been performed in multilayer energetic materials [3], but not much has been done in powder energetic composites. Here we report results of an investigation on the heat of combustion of consolidated $\mathrm{Ta}-\mathrm{WO}_{3}$ composites as a function of consolidation temperature using the spark plasma sintering (SPS) technique. 


\section{Experimental}

Energetic composites of Ta- $\mathrm{WO}_{3}$ were synthesized by two routes. In one we used a sol-gel (SG) derived method and in the second we mixed Ta and commercially available (CA) nanometric $\mathrm{WO}_{3}$ powders. Due to the lack of availability of nanometric tantalum, micrometric tantalum powder particles were used for both routes.

Figure 1 shows a secondary-electron scanning electron microscopy (SEM) image of the irregularly-shaped tantalum particles used in this work.

The SG derived Ta- $\mathrm{WO}_{3}$ mixture was made by dissolving $14.76 \mathrm{~g}(43.5 \mathrm{mmol})$ of $\mathrm{WOCl}_{4}(\mathrm{~F}$. W. $=339 \mathrm{gmol}^{-1}$; 98\% from Sigma-Aldrich, Milwaukee, WI) in $125 \mathrm{~mL}$ of an ethanol $/ \mathrm{H}_{2} \mathrm{O}$ solution with a $95 / 5 \mathrm{vol} \%$ composition. After filtering the solution, $9.2 \mathrm{~g}(52.2 \mathrm{mmol})$ of capacitor grade Ta metal (H.C. Starck; average particle size $5 \mu \mathrm{m}$ ) was added to the filtered solution to make a composite mixture. While stirring the composite mixture with a Teflon-coated stir bar on a magnetic stir plate, to ensure uniform distribution of the Ta fuel metal throughout the matrix, 20 $\mathrm{g}(235 \mathrm{mmol})$ of 3,3,-dimethyloxetane (DMO) was added to the mixture. A gelation of a uniform composite occurred shortly thereafter. This method provides an energetic composite that consisted of immobilized micrometric tantalum into a three-dimensional nanostructured tungsten oxide gel with a 6:5 $\left(\mathrm{Ta}: \mathrm{WO}_{3}\right)$ mole ratio. Further details on this method of synthesis of energetic composites can be found elsewhere ${ }^{8}$. The second preparation method consisted of mixing $48.2 \mathrm{wt} \%$ of the micrometric tantalum with $51.8 \mathrm{wt} \%$ of commercially available (CA) nanometric $\mathrm{WO}_{3}$. The commercially available $\mathrm{WO}_{3}$ was purchased from Sigma-Aldrich (Milwaukee, WI) and its average particle size was determined to be $48 \mathrm{~nm}$ by BET measurements ${ }^{13}$. The mixing of the CA energetic composite was carried out by grinding in a standard ceramic mortar and pestle for approximately $5 \mathrm{~min}$. Following the mixing, the powder mixture was placed in a glass vial and mixed further in a horizontal rolling mixer for another 5 $\min$.

The morphology of the Ta fuel in the energetic composite was examined using a Hitachi S4500 field emission scanning electron microscope (SEM) operated at $10 \mathrm{kV}$ in secondary-electron mode. The phase composition of each sample was determined by X-ray diffraction (XRD). The XRD was performed on a Scintag PAD V powder diffractometer operated at $45 \mathrm{kV}$ and $35 \mathrm{~mA}$ using $\mathrm{Cu} \mathrm{K}_{\alpha 1}$ radiation $(\lambda=1.54056 \AA)$. 
The consolidation of both the SG and the $\mathrm{CA}$ Ta- $\mathrm{WO}_{3}$ energetic composites was performed using the high-pressure spark plasma sintering (HPSPS) method. The technique is similar to hotpressing with the distinct difference that the heating is effected by a pulsed DC current applied to the sample and the graphite die. The graphite die assembly is made up of several internal components that allows for the application of pressures as high as $1 \mathrm{GPa}$. Further details on this technique are presented elsewhere ${ }^{14,15}$. Using $5 \mathrm{~mm}$ diameter graphite dies, the samples were consolidated at 25,400 and $500^{\circ} \mathrm{C}$. It should be noted that for the samples prepared at $25^{\circ} \mathrm{C}$, the pulsed DC current in the HPSPS technique was not applied. The samples that were consolidated to 400 and $500^{\circ} \mathrm{C}$ were subjected to a pressure of $150 \mathrm{MPa}$ and heated from room temperature to $200^{\circ} \mathrm{C}$ at approximately $50^{\circ} \mathrm{C} \mathrm{min}^{-1}$. Then the samples were held at $200^{\circ} \mathrm{C}$ for $2 \mathrm{~min}$ in order to remove any residual solvents or physically adsorbed water. Following the 2-min hold, the pressure was increased to $300 \mathrm{MPa}$ and the temperature increased to 400 or $500^{\circ} \mathrm{C}$ (at a rate of approximately $100^{\circ} \mathrm{C} \mathrm{min}^{-1}$ ) and held for $3 \mathrm{~min}$.

The heat of combustion was measured using an oxygen bomb calorimeter (Parr 1261 Isoperibol Bomb Calorimeter, Parr Instruments Co., Moline, IL). The thermal mass of the bomb was determined prior to the calorimetric measurements. Calibration of the bomb was accomplished by combusting several certified benzoic acid samples of a known mass in a pure oxygen (99.99\%) atmosphere. Once the thermal mass of the bomb was determined and the system calibrated, a Ta- $\mathrm{WO}_{3}$ sample weighing approximately $0.2 \mathrm{~g}$ was place inside the bomb. A Chromel (chromium-nickel alloy) wire was connected to the two electrodes in the bomb and placed in contact with the sample for ignition. The bomb is then assembled and sealed. The bomb was then purged twice by pressurizing it to $2.0 \mathrm{MPa}$ with oxygen. A third and final pressurization of the bomb was done at $2.0 \mathrm{MPa}$ and the assembly was placed inside the calorimeter. Further details on the bomb calorimetry method are given elsewhere ${ }^{16,17}$. The values reported here are averages of three separate measurements for each consolidation condition $\left(25,400\right.$ and $\left.500^{\circ} \mathrm{C}\right)$ and from each energetic composite type (SG and CA). Chemical analysis on the energetic composites was performed; Table 1 reports the average composition of each composite. 


\section{Results and Discussions}

The SG and the CA energetic composites were consolidated as outlined in the experimental procedure. The dependence of the relative density of the composites on the sintering temperature is shown in Figure 2. For samples consolidated at $25^{\circ} \mathrm{C}$, the average relative density for the SG composite was measured to be $50.87 \pm 1.39 \%$ as compared to $61.18 \pm 1.14 \%$ for the CA composite. A potential reason why the SG composite yields a lower density at $25^{\circ} \mathrm{C}$ than the CA composite could be because the SG composite is a three-dimensional network powder with open porosity. In contrast, the reactants in the CA composite are made up of individual particles without any open porosity within each particle. Therefore, as the SG composite is consolidated at $25^{\circ} \mathrm{C}$, the powder has to close the open porosity of the particles themselves and the gaps between each individual particle in the powder mixture. At sintering temperatures of 400 and $500^{\circ} \mathrm{C}$ the densities for both composites are within experimental uncertainties. Figure 2 shows that the average density for the SG composite is $73.31 \pm 0.58 \%$ and is $73.69 \pm 0.77 \%$ for the CA composite for samples consolidated at $400^{\circ} \mathrm{C}$. For samples consolidated at $500^{\circ} \mathrm{C}$, the average density for the SG composite was determined to be $76.13 \pm 0.62 \%$ and was $77.01 \pm 0.71 \%$ for the CA composite.

As provided by Fischer, et al. ${ }^{18}$, the theoretical heat of reaction for $\mathrm{Ta}-\mathrm{WO}_{3}$ is determined to be $0.857 \mathrm{~kJ} \cdot \mathrm{g}^{-1}$ and the heat of combustion of tungsten metal is $-4.585 \mathrm{~kJ} \cdot \mathrm{g}^{-1}$. Using these theoretical values and the known quantities of each reactant in the composite, the theoretical heat of combustion of Eq (1) is calculated as $-2.734 \mathrm{~kJ} \cdot \mathrm{g}^{-1}$.

$$
6 \mathrm{Ta}+5 \mathrm{WO}_{3}+7.5 \mathrm{O}_{2}(\mathrm{~g}) \rightarrow 3 \mathrm{Ta}_{2} \mathrm{O}_{5}+5 \mathrm{WO}_{3}
$$

The measured heats of combustion as a function of temperature of the SG-derived and the CA $\mathrm{Ta}-\mathrm{WO}_{3}$ composites are presented in Figure 3. As can be seen from the figure, the heat of combustion for the SG composite is higher than the theoretical value for samples consolidated at 25 and $400^{\circ} \mathrm{C}$. For samples consolidated at $500^{\circ} \mathrm{C}$, the measured heat of combustion is below the theoretical value. In comparison, the measured values for the CA composite are below the theoretical value for all conditions and decrease with increasing consolidation temperature. 
Elemental analyses were performed on both the SG and CA energetic composites. Table 1 shows that the $\mathrm{SG}$ composite contains an average of $2.52 \mathrm{wt} \%$ carbon. The presence of this carbon is likely the cause of the observed higher heats of combustion than the theoretical value. The excess carbon originates from the synthesis of the SG composites. Based on previous synthesis experiences, it is most likely that this carbon is in the form of a hydrocarbon with a structure similar to that of polypropylene oxide (PPO), a side product of the sol-gel process ${ }^{19}$. The theoretical heat of combustion of PPO is reported to be $-33.03 \mathrm{~kJ} \cdot \mathrm{g}^{-1}$. By subtracting the contribution of the hydrocarbon from the measured heat of combustion of the SG composite, the corrected heat of combustion for the SG composite becomes $-2.641 \mathrm{~kJ} \cdot \mathrm{g}^{-1}$. Moreover, if we apply the same correction to each of the measured values at each consolidation temperature, the measured values drop below the corrected theoretical heat of combustion value, see Figure 4. When comparing the corrected heat of combustion values of the SG to the measured heat of combustion values of the CA energetic composites, it can be observed from Figure 4 that the values for the SG are higher by $6-11 \%$ at all the consolidation temperatures.

X-ray diffraction patterns of the SG and CA samples were obtained for each of the consolidated pellets at each temperature. Figure 5 shows the diffraction patterns of pellets consolidated at $25^{\circ} \mathrm{C}$ for both the $\mathrm{SG}$ and the $\mathrm{CA}$ energetic composites. It can be observed that the SG derived composite is a mixture of crystalline Ta and amorphous $\mathrm{WO}_{3}$. In contrast, Figure 5 shows that the CA diffraction pattern indicates the presence of crystalline Ta and $\mathrm{WO}_{3}$.

As the consolidation temperature increases to $400^{\circ} \mathrm{C}$, the $\mathrm{Ta}$ and the $\mathrm{WO}_{3}$ begin to react in both the SG and the CA composite. Such reaction is indicated by the three high intensity peaks (labeled as peak 1, peak 2 and peak 3) next to the Ta peak located at $38.4^{\circ}(2 \theta)$ as shown in Figure 6. All three peaks have been identified as a Ta suboxide. The Ta suboxide that best fits these peaks is in the form of $\mathrm{TaO}_{\mathrm{x}}$ as presented by Brauer, et. al ${ }^{20}$. In addition, two other crystallographic changes occurred while consolidating $\mathrm{Ta}-\mathrm{WO}_{3}$ at $400^{\circ} \mathrm{C}$. The first change that can be observed is a decrease in the intensity of the $\mathrm{WO}_{3}$ peaks in the CA composite, as can be seen by comparing Figures 5 and 6 . The second crystallographic change is that the amorphous $\mathrm{WO}_{3}$ present in the SG composite as shown in Figure 5, has started to crystallize and react with the Ta to form some complex tantalum tungsten oxide, tungsten oxide and tungsten suboxide as 
observed by the presence of several peaks that were not present in Figure 5. Although it is difficult to properly identify these peaks, XRD analysis suggests that these peaks are from $\mathrm{Ta}_{\mathrm{y}} \mathrm{O}_{\mathrm{x}}$ $+\mathrm{WO}_{3-\mathrm{x}}, \mathrm{WO}_{3}$ and $\mathrm{WO}_{3-\mathrm{x}}$. Several studies have been perform on the oxidation of tantalum ${ }^{20,21}$ and oxidation of tungsten ${ }^{22}$ and have reported that these metals undergo several phase transformations as a function of increasing temperature. The appearance of tantalum suboxide and tungsten suboxide peaks, the reduction in intensity of the $\mathrm{WO}_{3}$ in the CA composite and the crystallization and reaction of the amorphous $\mathrm{WO}_{3}$ with the Ta metal in the $\mathrm{SG}$ composite indicates that the Ta and $\mathrm{WO}_{3}$ have begun to chemically react for samples consolidated to $400^{\circ} \mathrm{C}$.

The x-ray diffraction patterns of the $\mathrm{SG}$ and the $\mathrm{CA}$ composites consolidated at $500^{\circ} \mathrm{C}$ are presented in Figure 7. At this temperature, the reaction between the Ta and the $\mathrm{WO}_{3}$ has increased significantly (compare to Figure 5 and Figure 6). From the diffraction patterns it is apparent that $\mathrm{Ta}$ has reacted with the $\mathrm{WO}_{3}$ to form $\mathrm{Ta}_{2} \mathrm{O}_{5}, \mathrm{TaO}$, and $\mathrm{W}$ metal. For the $\mathrm{SG}$ energetic composite in Figure 7, it is seen that three of the most intense peaks, located at $2 \theta$ values of $22.98^{\circ}, 28.52^{\circ}$ and $36.96^{\circ}$, correspond to $\mathrm{Ta}_{2} \mathrm{O}_{5}$. Also it is noted that the intensity of the tantalum peak located at $2 \theta$ of about $38.4^{\circ}$ has decreased significantly in comparison to Figure 5. A similar trend to the $\mathrm{SG}$ composite is seen for the CA composite as shown in Figure 7. The difference between the $\mathrm{SG}$ composite and the $\mathrm{CA}$ composite consolidated at $500^{\circ} \mathrm{C}$ is that the most intense peak in the CA composite is broad and can be indexed to $\mathrm{TaO}, \mathrm{WO}_{3}$ and $\mathrm{W}$ metal, instead of the $\mathrm{Ta}_{2} \mathrm{O}_{5}$ as in the case for the $\mathrm{SG}$ composite. It is believed that since the CA composite does not incorporate immobilized Ta in the sol-gel matrix and instead is composed of individual fuel $(\mathrm{Ta})$ and oxidizer $\left(\mathrm{WO}_{3}\right)$ particles, the reaction rate between the reactants is slower since the diffusion lengths are longer. The slower reaction rate due to longer diffusion lengths may explain the reason why we observe a strong $\mathrm{TaO}$ and $\mathrm{W}$ metal intermediate phase.

It is likely that as the $\mathrm{WO}_{3}$ is reduced, as shown in Eq (2), it liberates oxygen gas and it oxidizes the tantalum metal present in the $\mathrm{Ta}-\mathrm{WO}_{3}$ composite. The oxidation of tantalum metal yields two distinct tantalum oxide phases as shown in Eqs (3) and (4). Hence, the reduction of tungsten oxide and the oxidation of tantalum in the $\mathrm{Ta}-\mathrm{WO}_{3}$ composite is a sequential process during the consolidating in HPSPS at 400 and $500^{\circ} \mathrm{C}$. 


$$
\begin{aligned}
& \mathrm{WO}_{3} \rightarrow \mathrm{W}+1.5 \mathrm{O}_{2}(\mathrm{~g}) \\
& 2 \mathrm{Ta}+\mathrm{O}_{2}(\mathrm{~g}) \rightarrow 2 \mathrm{TaO} \\
& 2 \mathrm{Ta}+2.5 \mathrm{O}_{2}(\mathrm{~g}) \rightarrow \mathrm{Ta}_{2} \mathrm{O}_{5}
\end{aligned}
$$

XRD scans of the pellets consolidated using HPSPS at a pressure of $300 \mathrm{MPa}$ and temperatures of 25,400 and $500^{\circ} \mathrm{C}$ show that the amount of pre-reaction between the $\mathrm{Ta}$ and the $\mathrm{WO}_{3}$ reactants in the energetic composite increases as a function of increasing consolidation temperature. A correlation can be found between the amount of pre-reaction of the constituents and the measured heat of combustion. Figure 3 shows that as the consolidation temperature increases the measured heat of combustion decreases. This can be attributed to fact that the pellets consolidated at $500^{\circ} \mathrm{C}$ experience higher degrees of pre-reaction in comparison to pellets consolidated at lower temperatures.

\section{Conclusion}

The heat of combustion of two distinctly synthesized stoichiometric $\mathrm{Ta}-\mathrm{WO}_{3}$ energetic composites was measured using bomb calorimetry as a function of consolidation temperature. The energetic composites were synthesized using a sol-gel method, which immobilizes the tantalum fuel in a three-dimensional tungsten oxide structure, and by the physical mixing of commercially available nanometric tungsten oxide with tantalum. Density measurements yield similar values for samples consolidated at 400 and $500^{\circ} \mathrm{C}$. In contrast, for samples consolidated at $25^{\circ} \mathrm{C}$, the measured density is about $10 \%$ lower for the composite made from the sol-gel derived tantalum-tungsten oxide composite. The lower density observed in the sol-gel derived composite could be due to the fact this composite is composed of a three-dimensional structure with open porosity which makes it difficult to densify in the absence of applied heat. Moreover, X-ray diffraction patterns show that the amount of pre-reaction between the constituents (Ta and $\mathrm{WO}_{3}$ ) increases as a function of consolidation temperature. Such increase in pre-reaction has a direct affect on the measure heat of combustion of the energetic composites. As the pre-reaction increases, the measured energy content decreases for both energetic composites. Ongoing 
studies are in progress to quantify the degree of pre-reaction at each of the consolidation temperatures $\left(25,400\right.$ and $\left.500^{\circ} \mathrm{C}\right)$.

\section{Acknowledgements}

This work was performed under the auspices of the U.S. Department of Energy by Lawrence Livermore National Laboratory under Contract DE-AC52-07NA27344. The authors are grateful to the Defense Threat Reduction Agency Advanced Energetics Program and the Joint DoD/DOE Munitions Technology Development Program for support of this project. To Professor Umberto Anselmi-Tamburini at the University of Pavia, in Italy for all his great scientific input. 
Table 1: Chemical composition by weight percent of sol-gel derived (SG) and commercially available (CA) $\mathrm{Ta}^{-\mathrm{WO}_{3}}$ energetic composite powders.

\begin{tabular}{lccc}
\hline & Ta [ \% ] & WO $_{3}[$ \% ] & C [ \% ] \\
\hline Sol-Gel (SG) & 45.70 & 51.78 & 2.52 \\
Commercially Available (CA) & 46.70 & 53.30 & $<0.5$ \\
\hline
\end{tabular}




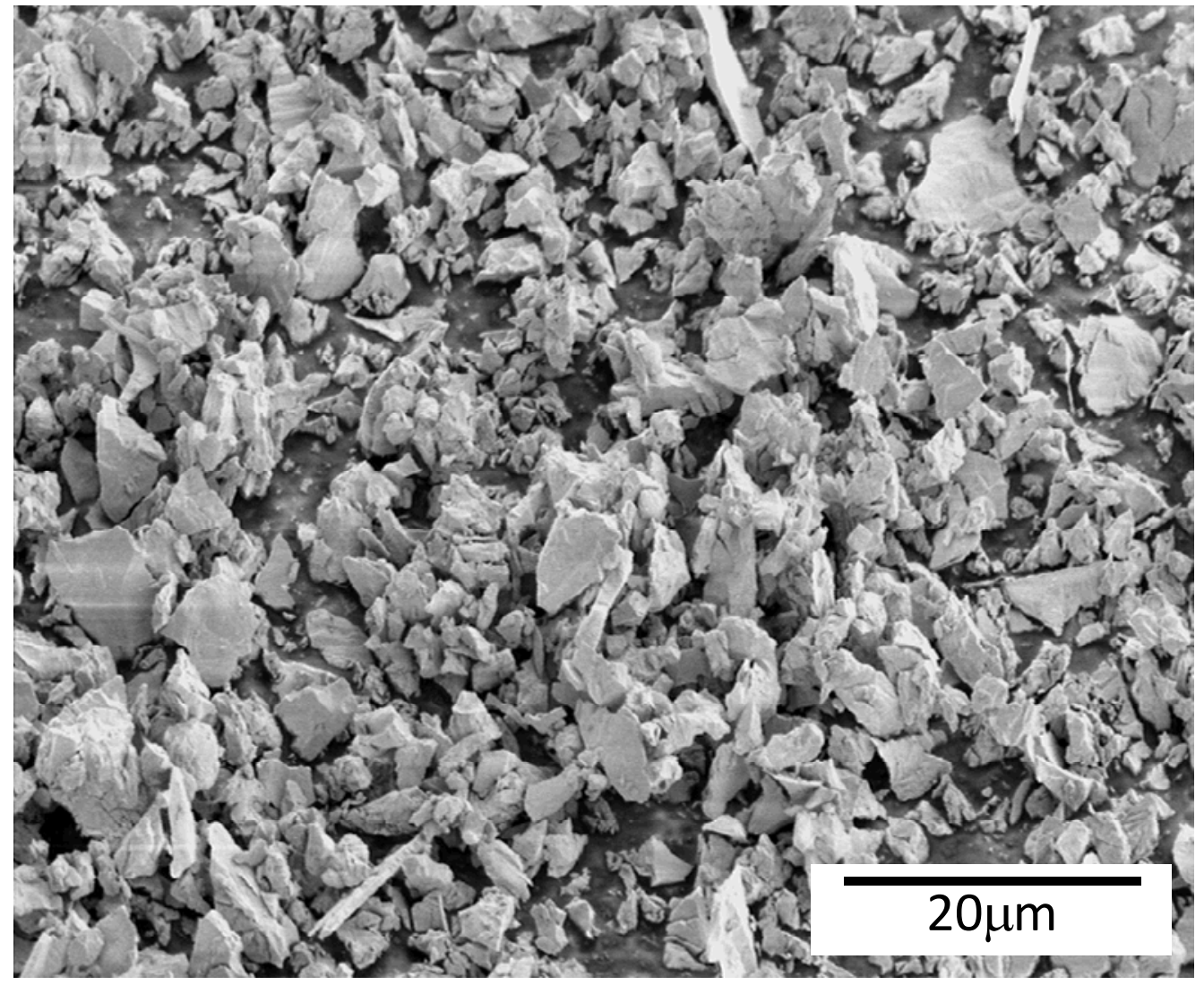

Figure 1: Secondary-electron SEM image of irregularly-shaped micrometric tantalum powder. 


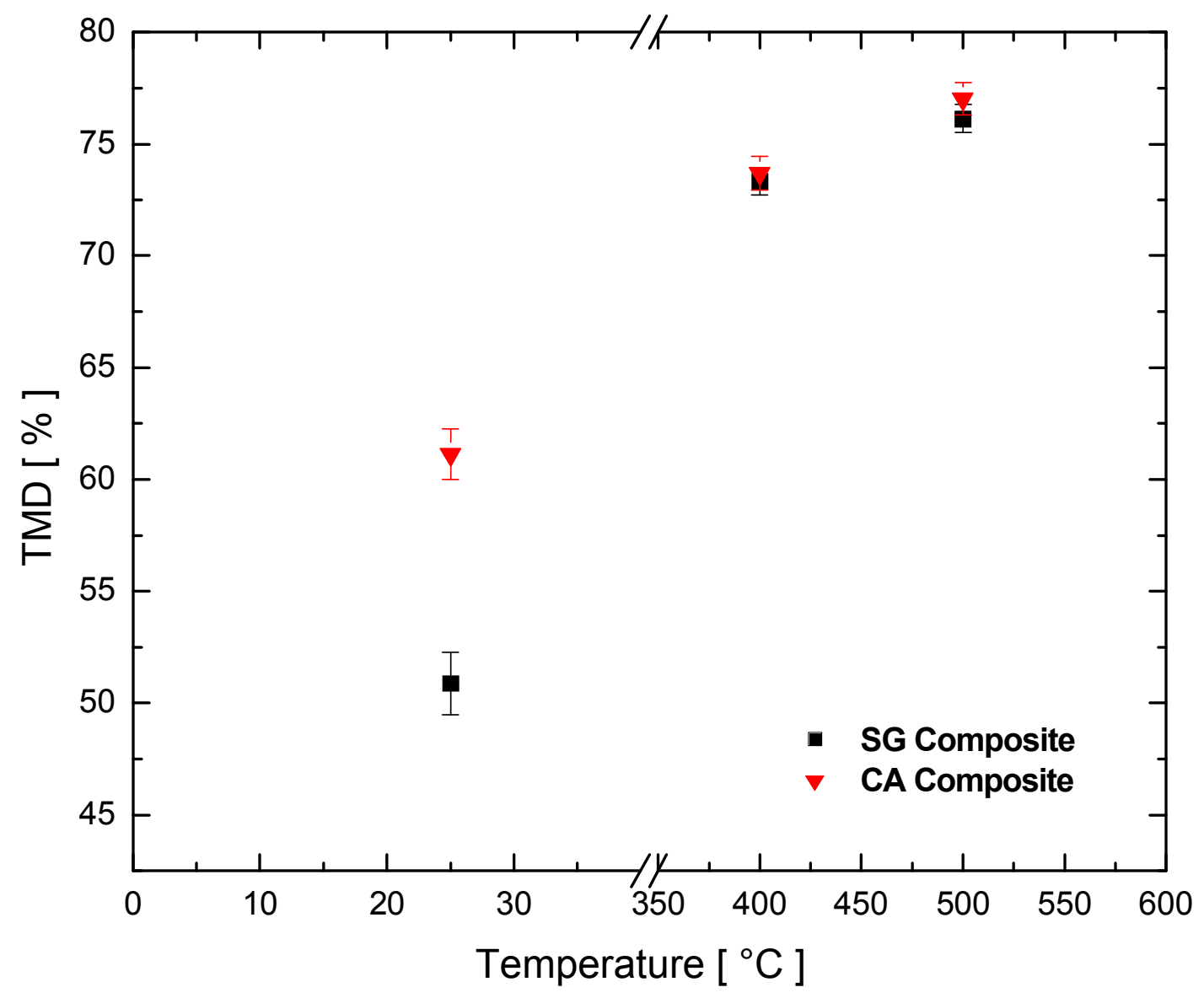

Figure 2: Theoretical Maximum Density vs consolidation temperature of both sol-gel (SG) derived and commercially available (CA) Ta-WO3 energetic composites. 


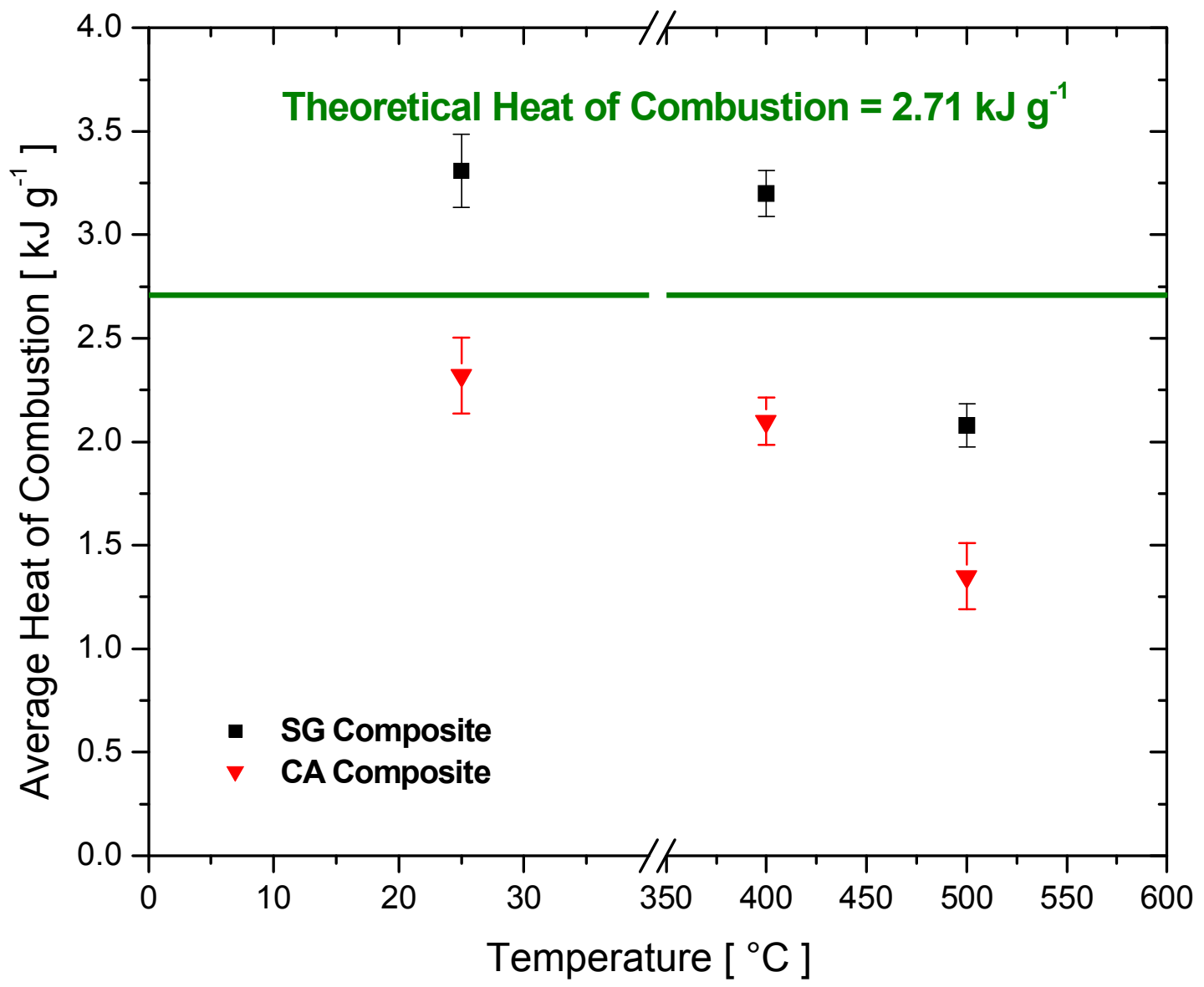

Figure 3: Average measured heat of combustion vs. temperature of SG and CA energetic composites. 


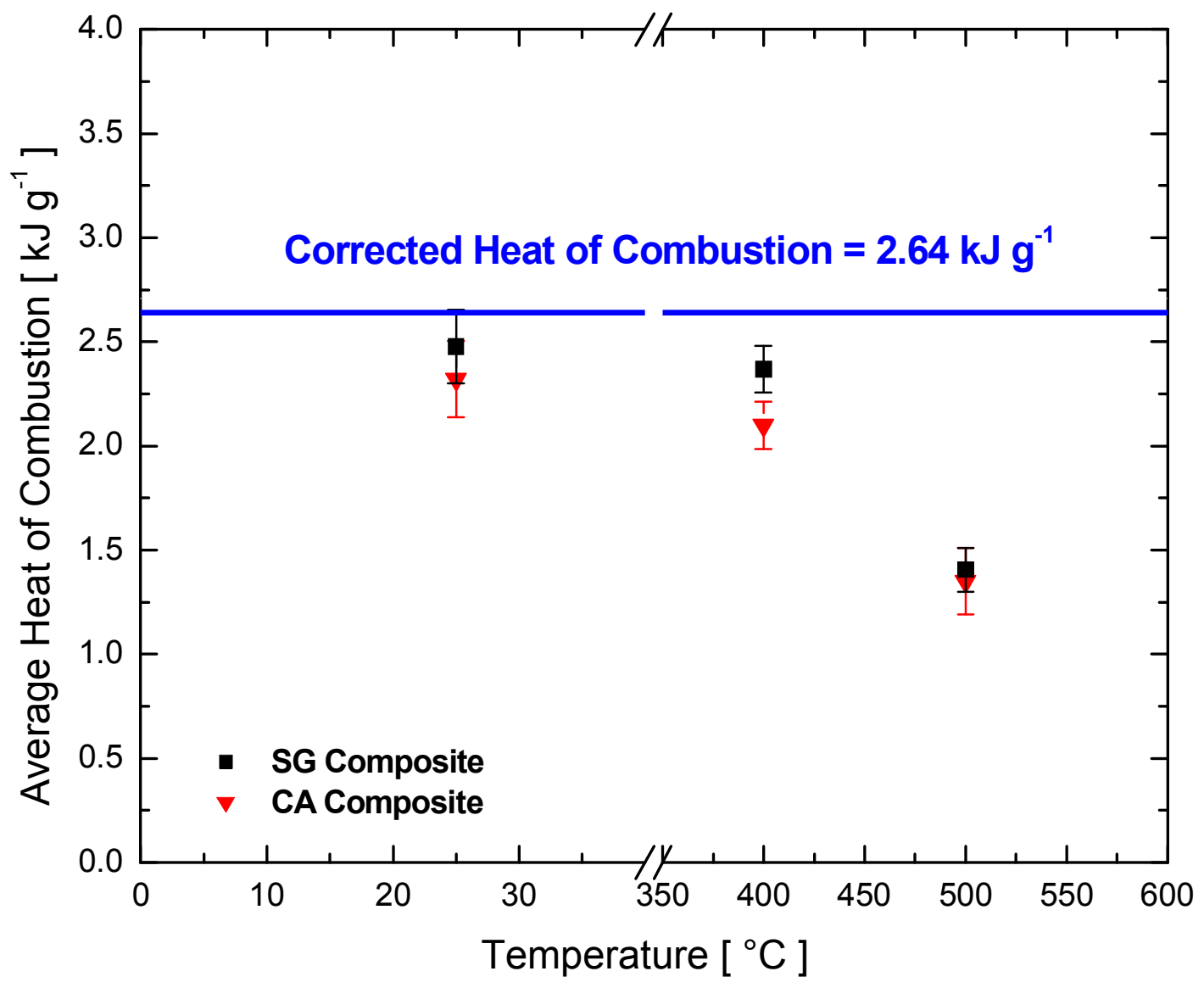

Figure 4: Corrected average measured heat of combustion vs. consolidation temperature of SG and $\mathrm{CA}$ energetic composites removing the contribution of the residual hydrocarbon in the SG derived energetic composite. 


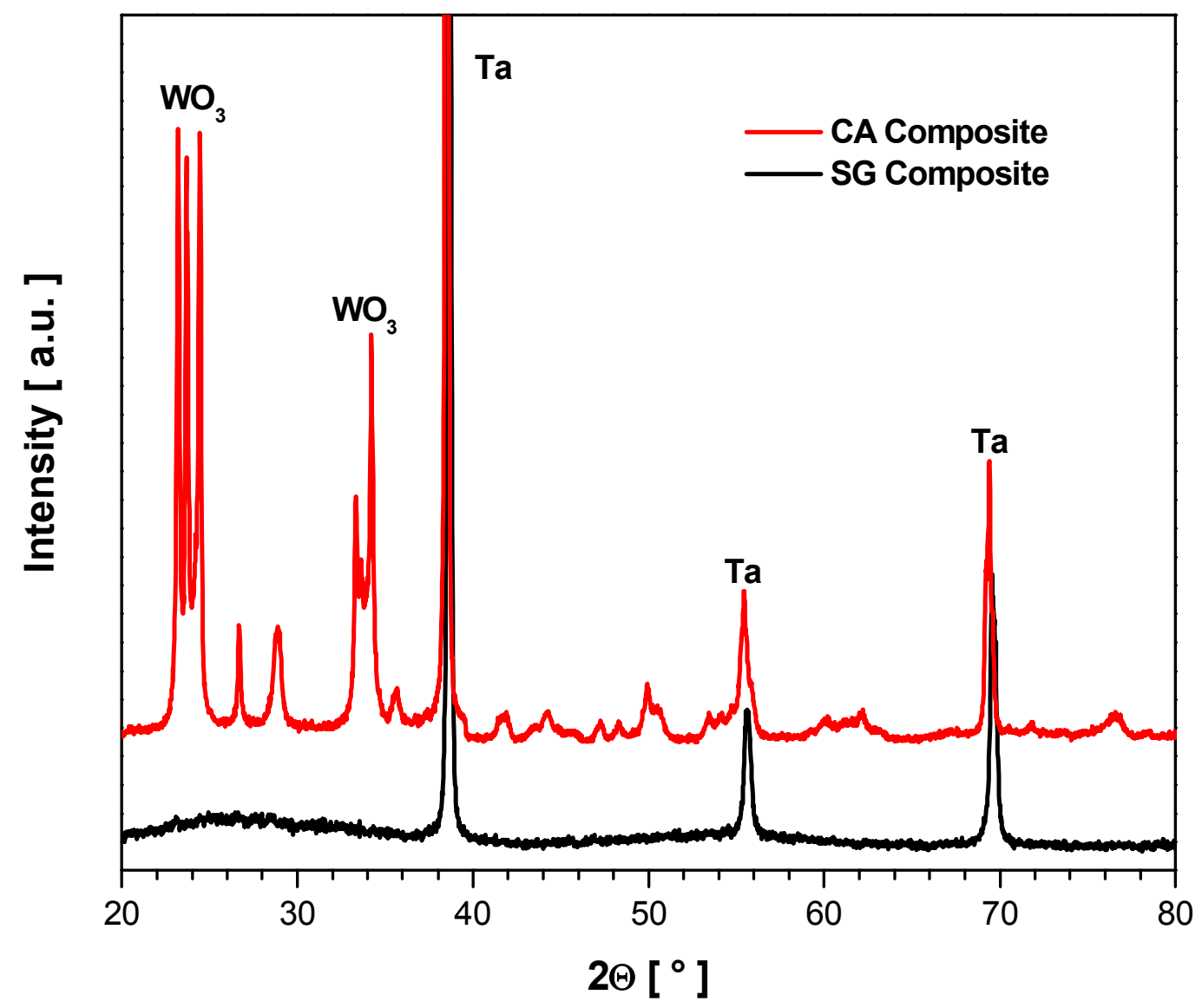

Figure 5: XRD of SG and CA energetic composite pellets consolidated using HPSPS to 300 $\mathrm{MPa}$ at $25^{\circ} \mathrm{C}$. 


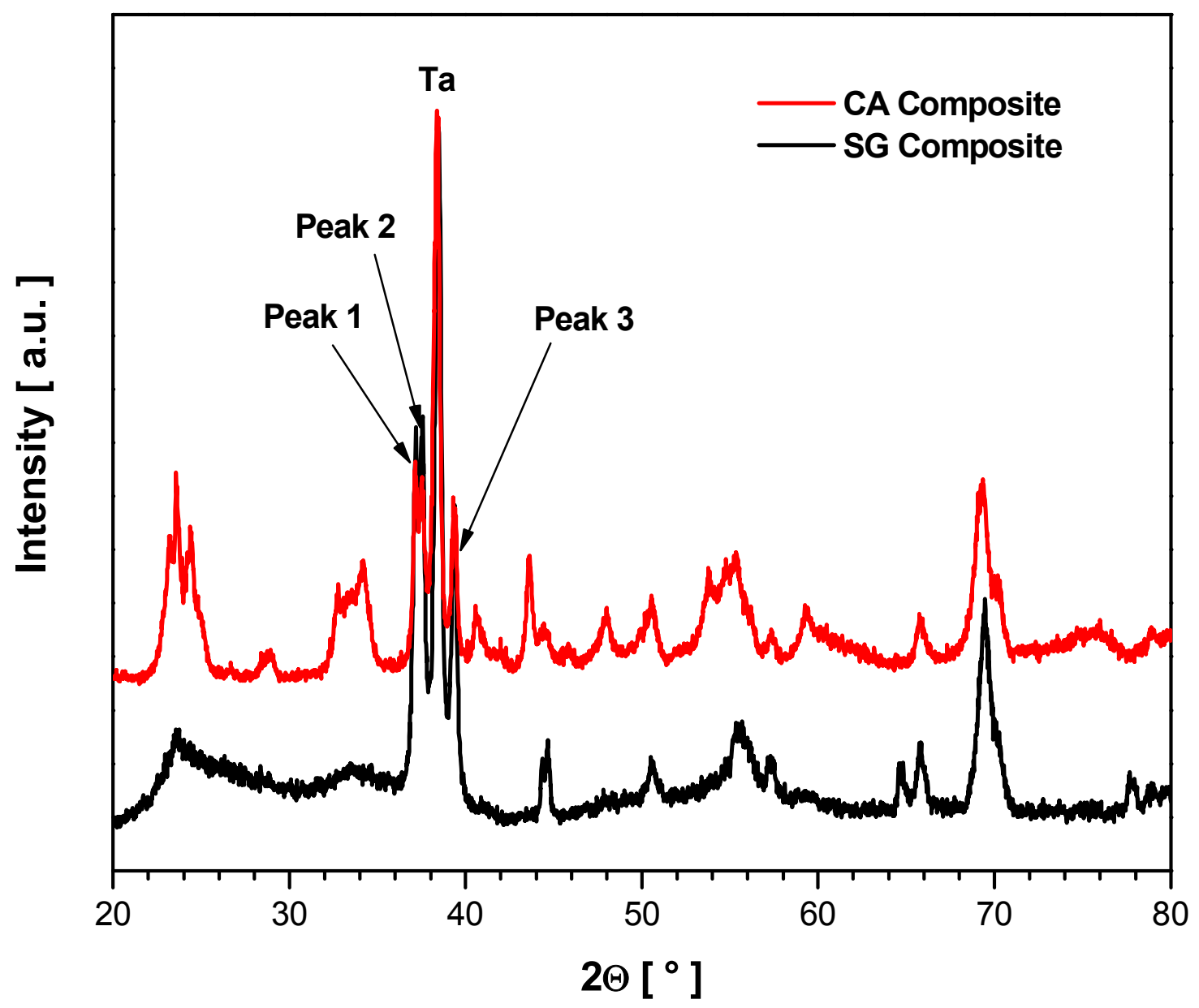

Figure 6: XRD of SG and CA energetic composite pellets consolidated using HPSPS to 300 $\mathrm{MPa}$ at $400^{\circ} \mathrm{C}$. 


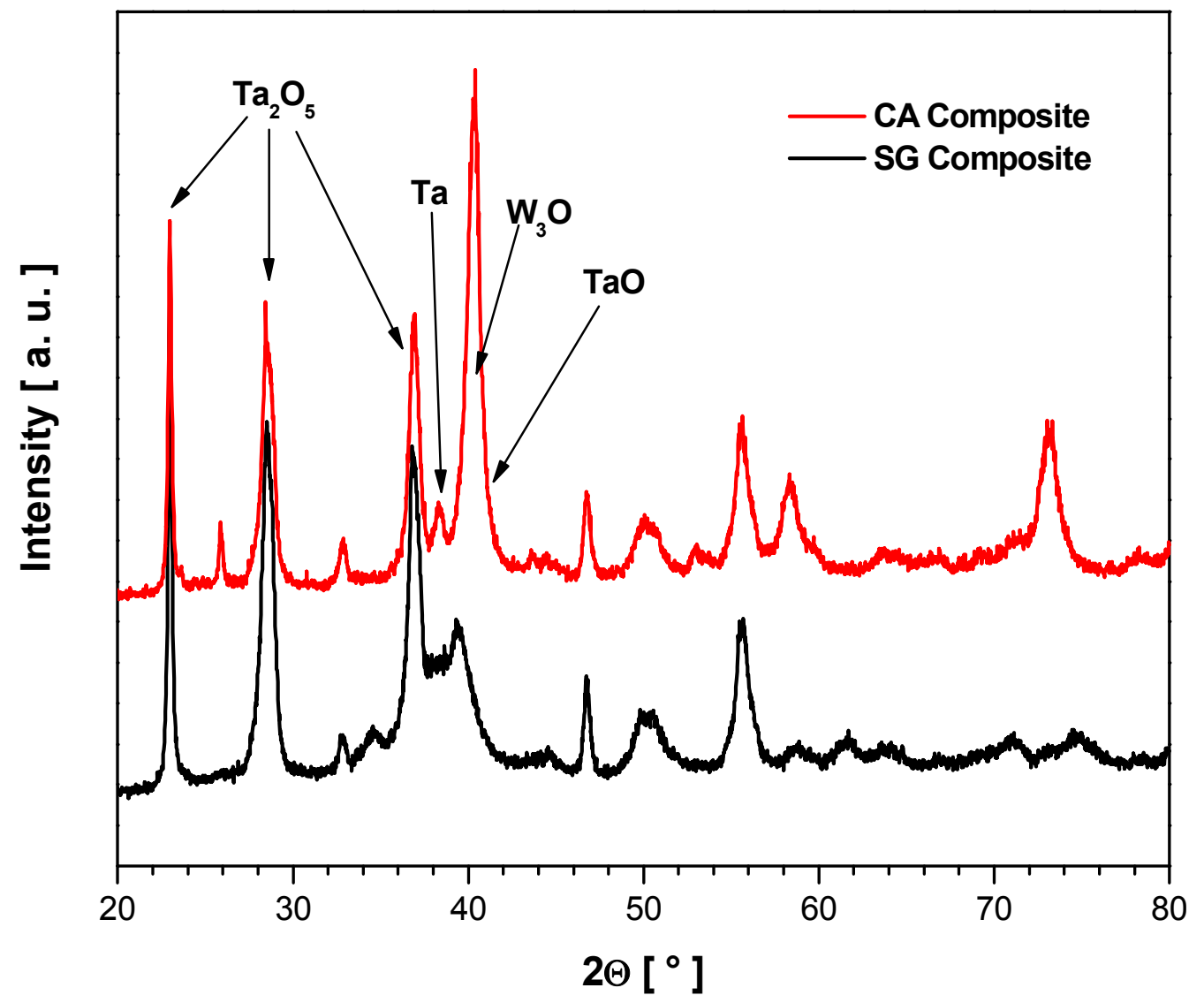

Figure 7: XRD of SG and CA energetic composite pellets consolidated using HPSPS to 300 $\mathrm{MPa}$ at $500^{\circ} \mathrm{C}$. 


\section{References}

1. T. S. Dyer; Z. A. Munir, Metallurgical and Materials Transactions B-Process Metallurgy and Materials Processing Science 1995, 26, (3), 603-610.

2. $\quad$ T. S. Dyer; Z. A. Munir; V. Ruth, Scripta Metallurgica Et Materialia 1994, 30, (10), 1281-1286.

3. K. J. Blobaum; M. E. Reiss; J. M. P. Lawrence; T. P. Weihs, Journal of Applied Physics 2003, 94, (5), 29152922.

4. K. B. Plantier; M. L. Pantoya; A. E. Gash, Combustion and Flame 2005, 140, (4), 299-309.

5. M. Schoenitz; T. S. Ward; E. L. Dreizin in: Fully dense nano-composite energetic powders prepared by arrested reactive milling, 30th International Symposium on Combustion, Chicago, IL, Jul 25-30, 2004; Chicago, IL, 2004; pp 2071-2078.

6. E. L. Dreizin; M. Schoenitz Nano-Composite Energetic Powders Prepared by Arrested Reactive Milling. Published in March 2006.

7. M. Schoenitz; T. Ward; E. L. Dreizin, Mater. Res. Soc. Symp. Proc. 2004, 800, AA2.6.1 - AA2.6.6.

8. J. D. Kuntz; O. G. Cervantes; A. E. Gash; Z. A. Munir, Chemistry of Materials 2009.

9. A. E. Gash; T. M. Tillotson; J. H. Satcher; L. W. Hrubesh; R. L. Simpson in: New sol-gel synthetic route to transition and main-group metal oxide aerogels using inorganic salt precursors, 6th International Symposium on Aerogels (ISA-6), Albuquerque, New Mexico, Oct 08-11, 2000; Albuquerque, New Mexico, 2000; pp 22-28.

10. T. M. Tillotson; A. E. Gash; R. L. Simpson; L. W. Hrubesh; J. H. Satcher; J. F. Poco in: Nanostructured energetic materials using sol-gel methodologies, 6th International Symposium on Aerogels (ISA-6), Albuquerque, New Mexico, Oct 08-11, 2000; Albuquerque, New Mexico, 2000; pp 338-345.

11. J. J. Granier; M. L. Pantoya, Combustion and Flame 2004, 138, (4), 373-383.

12. C. E. Aumann; G. L. Skofronick; J. A. Martin, Journal of Vacuum Science \& Technology B 1995, 13, (3), 1178-

1183.

13. S. Brunauer; P. H. Emmett; E. Teller, Journal of the American Chemical Society 1938, 60, 309-319.

14. U. Anselmi-Tamburini; J. E. Garay; Z. A. Munir, Scripta Materialia 2006, 54, (5), 823-828.

15. Z. A. Munir; U. Anselmi-Tamburini; M. Ohyanagi, Journal of Materials Science 2006, 41, (3), 763-777.

16. F. Daniels, Journal of the American Chemical Society 1916, 38, 1473-1480.

17. D. P. Shoemaker; C. W. Garland; J. W. Nibler, 1996, 6th Edition, 152 - 158.

18. S. H. Fischer; M. C. Grubelich, Proc. of the 24th Int. Pyrotechnics Seminar 1998.

19. A. E. Gash; T. M. Tillotson; J. H. Satcher; J. F. Poco; L. W. Hrubesh; R. L. Simpson, Chemistry of Materials 2001, 13, (3), 999-1007.

20. G. Brauer; H. Muller; G. Kuhner, Journal of the Less-Common Metals 1962, 4, (6), 533-546.

21. R. S. Roth; J. L. Waring; H. S. Parker, Journal of Solid State Chemistry 1970, 2, (3), 445-461.

22. L. Maille; C. Sant; C. Le Paven-Thivet; C. Legrand-Buscema; P. Garnier in: Structure and morphological study of nanometer $W$ and W3O thin films, Symposium on Growth and Evolutio of Ultra Thin Films held at the 2000 European-Materials-Research-Society Spring Meeting, Strasbourg, France, Jun 18-21, 2000; Elsevier Science Sa: Strasbourg, France, 2000; pp 237-241. 